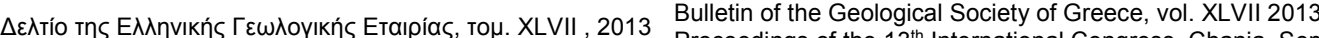
Proceedings of the $13^{\text {th }}$ International Congress, Chania Sept.

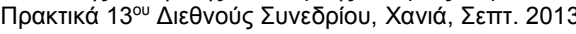
2013

\title{
USE OF MINE PLANNING SOFTWARE FOR THE EVALUATION OF RESOURCES AND RESERVES OF A SEDIMENTARY NICKEL DEPOSIT
}

\author{
Kapageridis I. ${ }^{1}$, Apostolikas A. ${ }^{2}$, Pappas S. ${ }^{2}$ and Zevgolis I. ${ }^{2}$ \\ ${ }^{1}$ Department of Geotechnology and Environmental Engineering, Technological Educational \\ Institute of Western Macedonia, Koila, 50100, Kozani, Greece, ikapa@teikoz.gr \\ ${ }^{2}$ LARCO GMMSA, 81-83 Kifisias Avenue, Athens, Greece
}

\begin{abstract}
The use of mine planning software in the evaluation of deposits and estimation of mineral resources and reserves has become widespread and is considered a prerequisite for the reporting of reserves according to international reporting standards and codes. The main principles of operation and application of these codes are transparency of reported material, the relevance of reported information (materiality) and the competence of people involved in producing the reports. The application of specialised mine planning software described in this paper currently takes place at operational mines of sedimentary nickel deposits in Central Evia, Greece. It involves all stages of processing of exploration data including entry, analysis, processing and modelling of data, geostatistical estimation of quantities and qualities of mineral resources and mineral reserves, and the design, optimisation and scheduling of mining operations.
\end{abstract}

Key words: geostatistics, pit optimisation, reporting standards.

\section{Пєрí $\eta \psi \eta$}

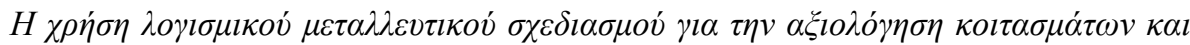

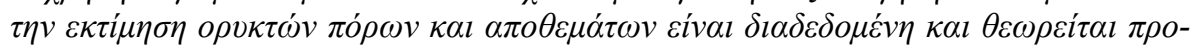

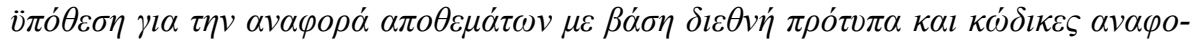

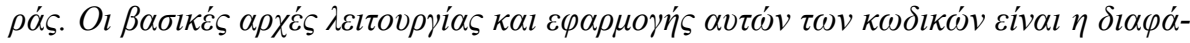

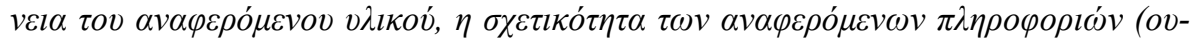

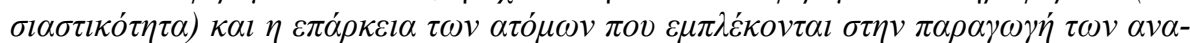

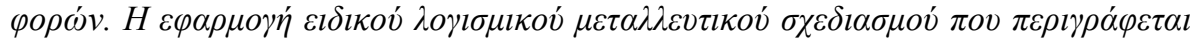



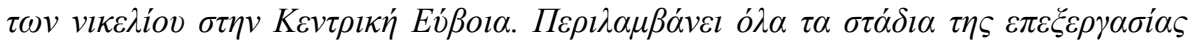

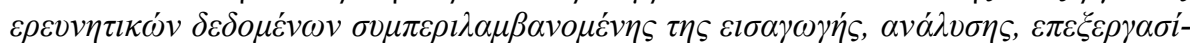

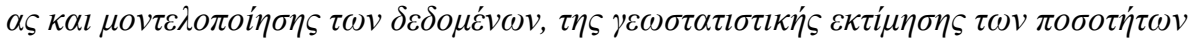



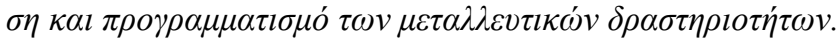

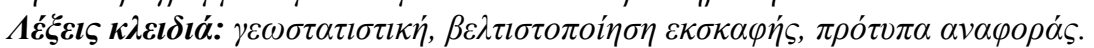

XLVII, No 3 - 1980 


\section{Introduction}

\subsection{Geological Setting}

The nickeliferous mineralization in Greece is related to the geotectonic zones of Almopia, Pelagonian and Sub-Pelagonian, - the main metalliferous regions are situated in Locris, Euboea and Kastoria. In Central Euboea, iron and nickel ores of Cretaceous age occur, which are of sedimentary type and consist of stratified lenses and layers, overlain by Upper Cretaceous limestones and underlain by ophiolites (and in exceptional cases by Jurassic limestones). The mineralization is either pissolitic or compact with silcretes developed within the ore, the development of lenticular intercalations or siliceous layers is also common, while silcretes are also found in the bedrock. A large number of significant deposits exist in the Psachnon area, the Akres, Katsikiza, Isomata and the Katavolo-Fterada in the Kimi's area. The deposit used in the study presented in this paper is from the Akres area (Figure 1).

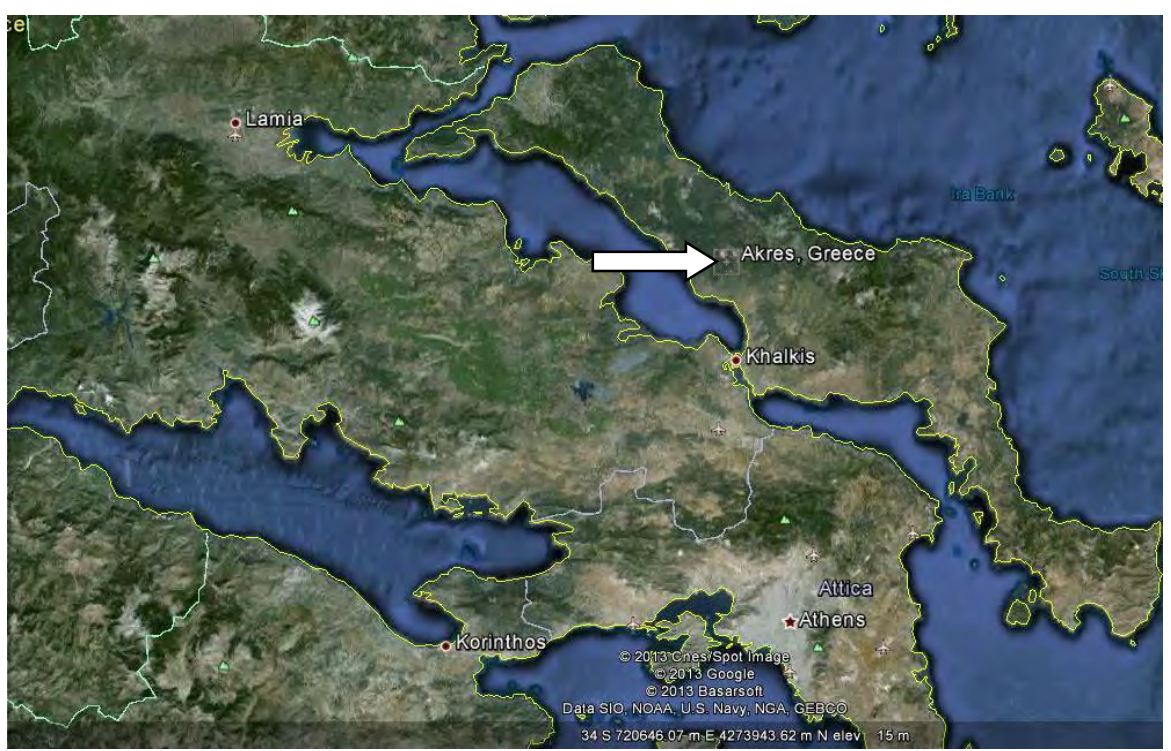

Figure 1 - Location of Akres deposits in Euboea.

\subsection{Available Data}

Drilling information from 126 surface drillholes from the NE Akres deposit was provided for the purposes of this study in the form of CSV files. This data was imported to a drillhole database in Vulcan. The database has four tables to hold collar, survey, lithology and assay information. The database was validated using a number of checks for overlapping intervals, numerical field ranges (coordinates and grade fields), and numeric order (lithology and assay interval fields). The drillhole lithological information was used to model the boundaries of the orebody in three dimensions. The assay information was used to perform structural analysis (variography) of the nickel spatial distribution and grade estimation on the basis of a block model. Financial and technical information concerning the mining and processing methods used were also available and were used in the pit optimisation and design stages of the study.

\subsection{Procedure}

The modelling and resource/reserve estimation study presented in this paper was performed in a number of steps using Maptek's Vulcan 3D software - one of the major commercial mine planning packages implemented by LARCO SA since 2007. The implementation of industry standard software based mine planning techniques aimed at meeting the requirements set by international 
reporting codes (SAMREC, 2009, JORC, 2012, NI 43-101, 2011, and PERC, 2013). These techniques regarded database generation and validation, statistical analysis and compositing of samples, geological modelling of the orebody, structural analysis (variography), grade estimation on a block model basis, pit optimisation and design, and reporting of resources and reserves. All steps were supervised by qualified personnel as required by reporting codes. The implementation of reporting code guidelines to resources and reserves estimation and reporting using mine planning software has been examined in the past by Snowden (1996), Duke et al. (1999), and Kapageridis (2007).

\section{Geological Modelling}

\subsection{Orebody Boundaries Modelling}

The structural roof and floor of the main orebody area and of an internal low grade envelope were modelled using grid model interpolation based on drillhole lithological intervals. The highest points of a particular lithology code (20) which corresponds to the main orebody area were derived from the database and were used to generate a grid model of the roof. The same procedure was used to model the floor from the lowest points of the same lithology code. The triangulation algorithm with trending was used to interpolate grid points between drillholes in all cases. Figure 2 shows a section through all four structural surfaces.

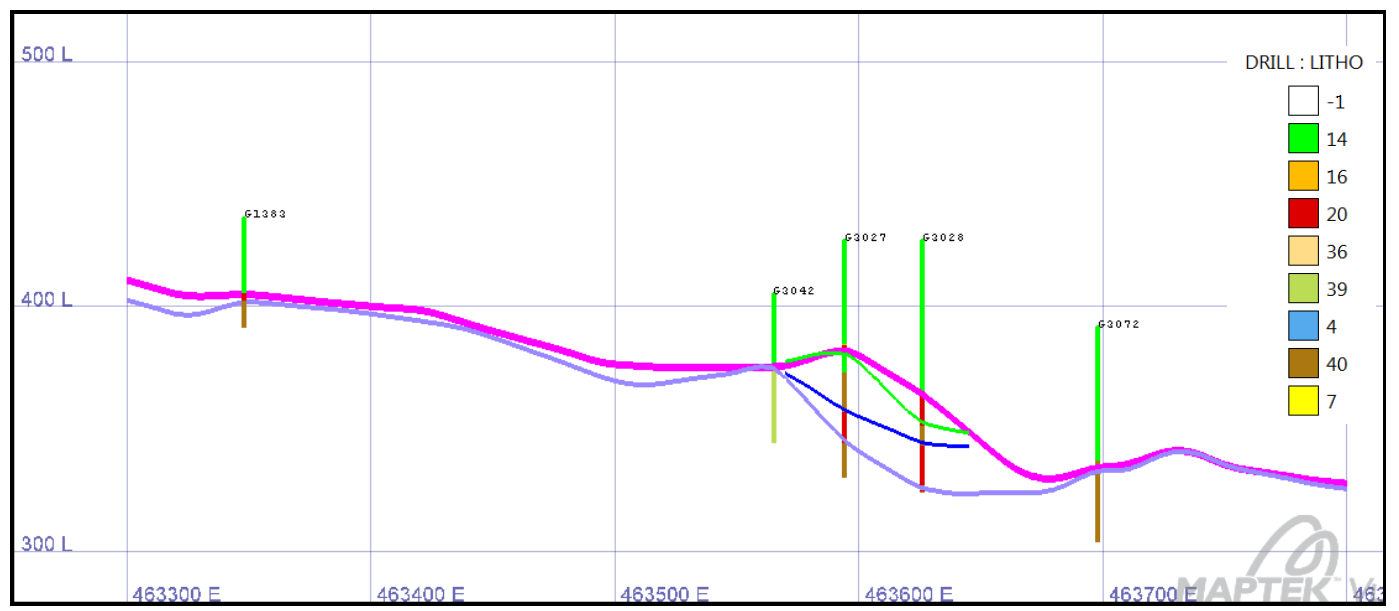

Figure 2 - West-East section looking North showing roof and floor models of main orebody area and internal low grade envelope derived from drillhole lithological intervals.

\subsection{Unfolding Orebody Deformities}

A number of methods for modelling deformations produced by various folding mechanisms have been developed. Earlier methods of unfolding deposits were based on various geometrical, mathematical or even manual techniques such as least squares, cylindrical unfolding or the fitting of splines (Royle 1979, Dagbert et al. 1983, Dowd 1986). Other more recent methods were based on the use of an unfolded coordinate system for the transformation of every sample and every estimation point for variography and grade estimation (Newton 1995). Tetrahedral modelling for variography and grade estimation was developed by Trevor Coulsen in 1995 (Maptek Pty Ltd) and implemented in Maptek's VULCAN 3D software package. Further improvements to the original algorithm were made by Peter Borovina (Maptek Pty Ltd) in 2002. Tetrahedral modelling is a method of adjusting the search ellipse used in variography and grade estimation to follow the geometrical structure of the deposit by forming a 3D tetrahedral model of the deposit volume. For this model to be generated, the structural surfaces of the deposit need to be modelled as surface triangulations. In tetrahedral modelling the search ellipse is distorted to follow nominated

$\underline{\text { XLVII, No } 3-1982}$ 
structural surfaces leading to improved estimation accuracy (Kapageridis, 2006) and improved classification of resources.

A tetrahedral model was generated in this study using the structural roof and floor models of the main orebody area. This model (Figure 3) captured the orientation and shape of all deformities as represented by the structural models and was used to bring samples to an unfolded location relative to blocks during grade estimation.



Figure 3 - 3D representation of tetrahedral model used in unfolding.

\section{Variography - Grade Estimation}

\subsection{Statistics and Sample Compositing}

General statistics and histograms of nickel grade were calculated to gain a better understanding of its distribution characteristics. Original assay intervals were then composited to standard length composites $(1 \mathrm{~m})$ to derive a set of equal support values to use for variography and grade estimation. The choice of composite length was based on the selectivity of the mining method used in this deposit and also on the effect of the compositing to the statistical characteristics of the composited values.

\subsection{Variography - Structural Analysis}

In order to model the structure underlying the $\mathrm{Ni}$ grade distribution represented by the available composites, fix the search region to be used during sample selection, and provide a model to ordinary kriging for weights calculation, structural analysis was performed using only the composites from the main orebody area. The procedure applied to derive the final variogram model is discussed in the following paragraphs.

\subsubsection{Downhole Variography - Nugget Effect Approximation}

Downhole variography was performed in order to set the nugget effect presented by the composites used in this study. The standard semivariogram was used in this study as the mode for experimental variography. The downhole variogram was calculated using nickel composited values, a lag of $1 \mathrm{~m}$ to match the composite length, 30 lags, and a lag tolerance of $0.3 \mathrm{~m}$. Figure 4 below displays the experimental downhole semivariogram and the fitted model. The range and sill displayed was also used for the final variogram model as the drillholes are all vertical, hence correspond to a particular direction in space. The fitted value for the nugget effect was 0.002 . This value was used in the final variogram model fitted in different directions.

$\underline{\text { XLVII, No } 3-1983}$ 
SEMI $\quad \exists Z=90 \quad$ 口I $=-90$

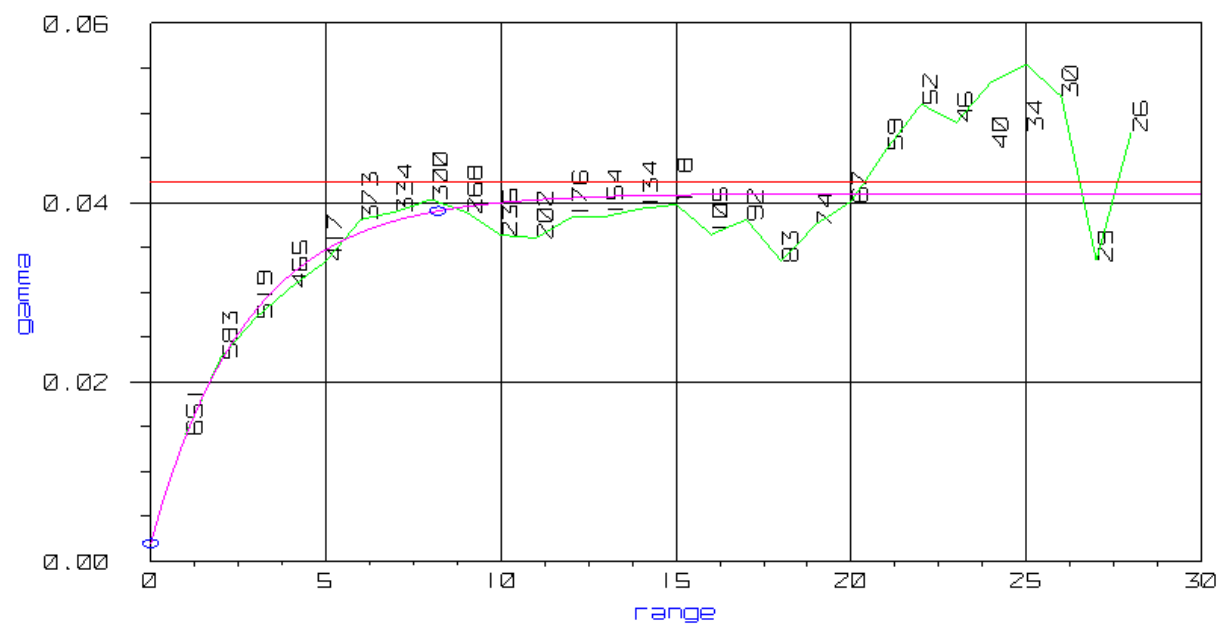

Figure 4 - Downhole experimental semivariogram and fitted exponential model.

\subsubsection{Directional Variography}

Directional experimental variograms of the Ni composited values were calculated in various directions and were used to fit a model. A lag size of 10 was used in all directions and a total number of 15 lags were calculated, i.e. a semivariogram value was calculated every $10 \mathrm{~m}$ and up to $150 \mathrm{~m}$. A lag tolerance of $2 \mathrm{~m}$ was used to allow for irregularities of the drilling pattern. Azimuth and plunge tolerances were set to $20^{\circ}$ and a horizontal and vertical bandwidth of $20 \mathrm{~m}$ was applied. Figure 5 explains in graphical form the way these parameters are applied when searching for pairs of samples to calculate experimental variogram points.

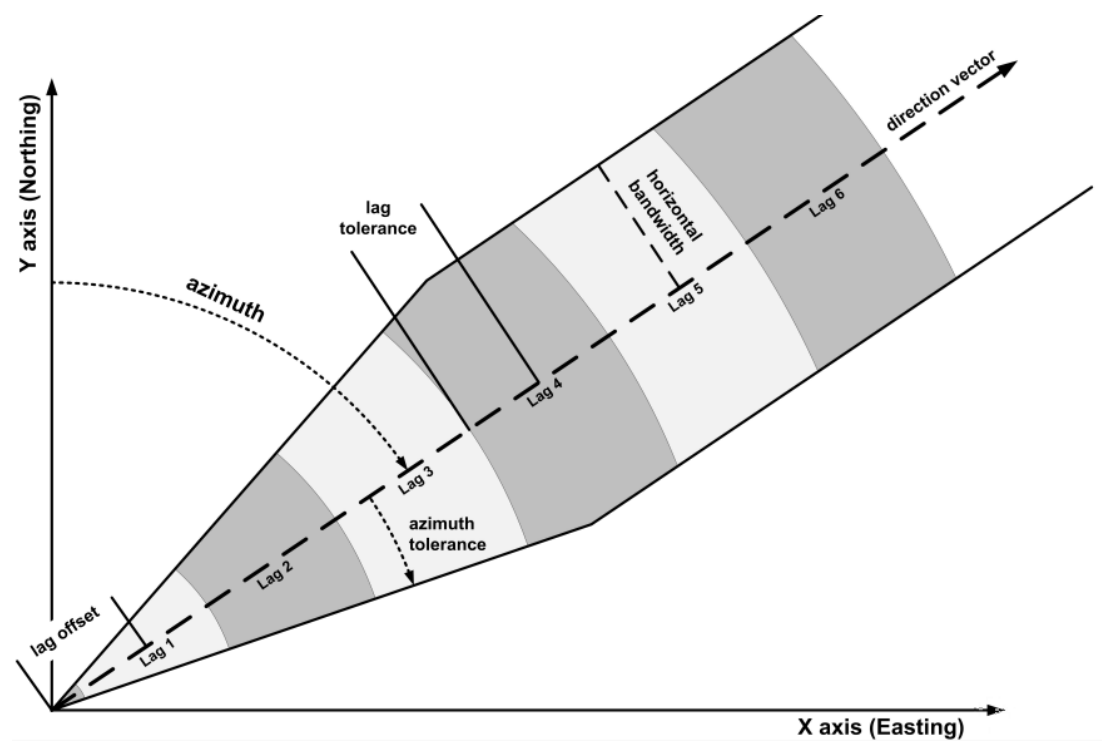

Figure 5 - Explanation of lag and direction setup parameters for directional variography.

\subsubsection{Variogram Model}

A variogram model consisting of a single exponential structure was fitted to the experimental variogram as shown in the two indicative directions in Figure 6. The exponential model was 
chosen as it seemed to match better the curvy shape of the experimental variogram at distances between 0 and 50 meters. The spherical model which is the most common choice in similar studies, has an almost linear beginning that did not fit well in this case. Table 1 gives the parameters of the final variogram model used for grade estimation.
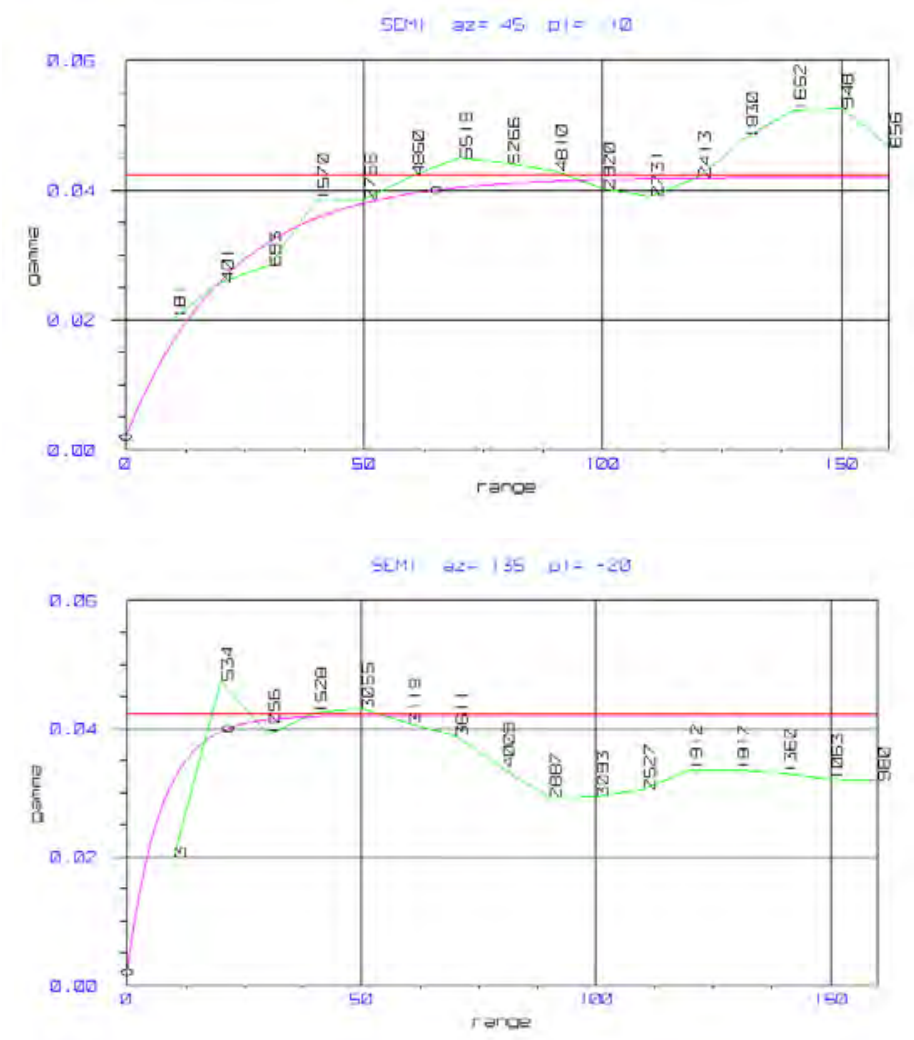

Figure 6 - Experimental semivariograms and fitted exponential model (point labels are pair counts).

Table 1 - Fitted Variogram Model Parameters.

\begin{tabular}{|l|c|}
\hline Experimental Variogram Type & Standard Semivariogram \\
\hline Fitted Model Type & Exponential \\
\hline Nugget Effect & 0.002 \\
\hline Sill Differential & 0.04 \\
\hline Bearing & 45 \\
\hline Plunge & -15 \\
\hline Dip & 0 \\
\hline Major range & 65 \\
\hline Semimajor range & 42.85 \\
\hline Minor range & 8.2 \\
\hline
\end{tabular}




\subsection{Grade Estimation and Resource Classification}

A block model with $10 \times 10 \times 12 \mathrm{~m}$ main blocks and a minimum sub-block size of $1 \times 1 \times 1 \mathrm{~m}$ was generated covering the entire area of the deposit. The main and sub-block sizes were set to reflect pit geometry and mine method selectivity. The model was not rotated around any axis in order to be used for pit optimisation. Ordinary Kriging $(\mathrm{OK})$ was used as the method for interpolating $\mathrm{Ni}$ values to the blocks coded as part of the main orebody. OK used the fitted variogram model consisting of a single exponential structure as described in Section 3.2. Three separate estimation runs were performed, each with different sample selection strategies and varying search ellipsoid dimensions, corresponding to three different resource classifications. In each run the blocks estimated received a flag in the class variable of the block model according to the classification: 1 for measured, 2 for indicated, and 3 for inferred. Blocks estimated with the 1st run (measured) were excluded from the 2 nd run (indicated), and blocks estimated with the 1 st and 2 nd run were excluded from the 3 rd run (inferred). Table 2 summarises the parameters used in each run and then number of blocks estimated.

Table 2 - Summary of Grade Estimation Parameters.

\begin{tabular}{|l|c|c|c|}
\hline & Measured & Indicated & Inferred \\
\hline Bearing & 45 & 45 & 45 \\
\hline Plunge & -10 & -10 & -10 \\
\hline Dip & -25 & -25 & -25 \\
\hline Major & 32.5 & 65 & 65 \\
\hline Semi & 21.4 & 42.8 & 42.8 \\
\hline Minor & 8.2 & 8.2 & 8.2 \\
\hline Minimum Samples & 8 & 4 & 4 \\
\hline Maximum Samples & 16 & 16 & 16 \\
\hline Octant Based Search & Yes & Yes & No \\
\hline Maximum Samples per Octant & 2 & 2 & - \\
\hline Minimum Octants & 4 & - & - \\
\hline Minimum Samples per Octant & 2 & - & - \\
\hline Blocks Estimated & 9958 & 27528 & 1 \\
\hline
\end{tabular}

\section{Pit Optimisation and Design}

\subsection{Estimation and Application of Technical and Financial Parameters}

Technical and financial parameters related to the mine geometry and location, mining method, haulage and ore processing were calculated for each block individually using a script written in Perl and utilising Vulcan's Lava extensions to this popular scripting language. The parameters set by the script and the values used for the purposes of this study are shown as entered in the panel in Figure 7. The calculated values for the various parameters were used to estimate a total block value that was used for pit optimisation using the following equation:

$$
\begin{aligned}
& \text { block_value }=\text { revenue }- \text { mining_cost }- \text { haulage_cost }- \text { crushing_cost }- \text { metallurgy_cost }- \\
& \text { sea_transport_cost-other_block_cost }
\end{aligned}
$$

The values for the each of the parameters were also stored in separate block model variables for validation purposes. Through this process, all the applicable resources to reserves conversion 
parameters according to reporting standards were applied to the resource block model before using it for pit optimisation.

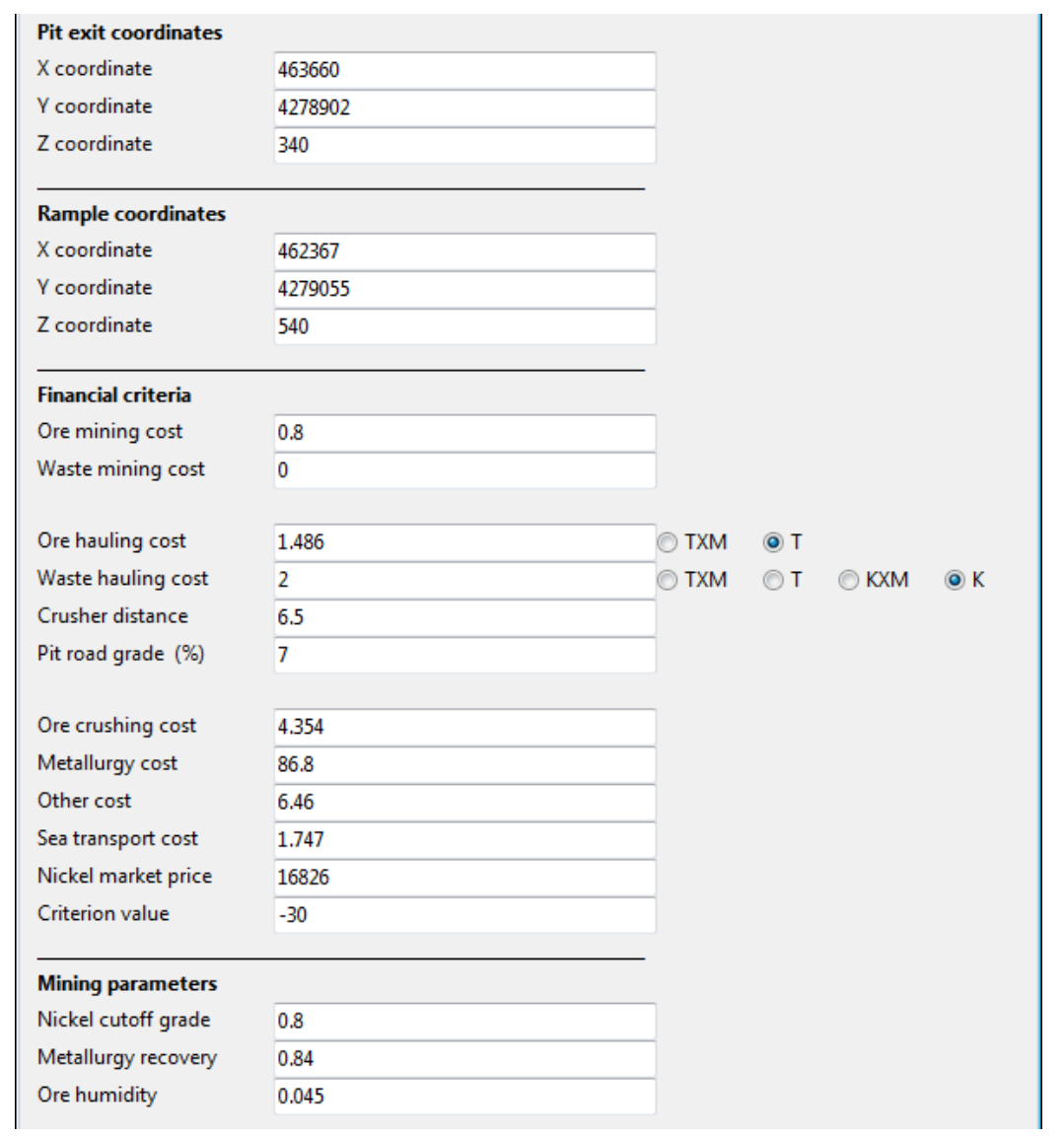

Figure 7 - Configuration panel for pit optimisation mining and financial criteria generated by the script.

\subsection{Pit Optimisation}

The block value calculated in the previous step was passed to Vulcan's Pit Optimiser module - an implementation of the Lerchs-Grossman algorithm. Two different angles were used to control the slope of the final pit limits, matching the bench angle and height, and berm width configuration and also allowing for the presence of haul road on one side of the pit. A $45^{\circ}$ pit slope was used in the East side of the pit and a $25^{\circ}$ slope in the west side (the side of the haul road). The pit slope was also controlled by a lithology block model variable. The result of pit optimisation was stored as a code in a block model variable. Blocks that belong to the optimum pit (including ore and waste blocks) receive a different value from those that do not. This way, a subset of the resource blocks were converted to potential reserve blocks. However, the optimum pit as presented by the contours shown in Figure 8 is not a complete pit design and can only be used as a guide for the next important step of designing a feasible pit.

\subsection{Pit Design}

Pit design was performed using the optimum pit limits as a guide (Figure 8). The top part of the pit from the lowest open bench, i.e. the lowest bench that could be accessed from the surface, was 
designed with projections upwards and outwards of the corresponding optimum pit limit to generate the toe and crest polygons without a haul road. The bottom part of the pit from the highest closed bench, was designed using a more complex function in Vulcan that inserts the haul road and then projects the toe and crest polygons for each bench. Two switchbacks were introduced to maintain the haul road only on the west side of the pit as this was the side with the lower pit slope set in pit optimisation. The benches were $12 \mathrm{~m}$ high with $8 \mathrm{~m}$ berms and a $70^{\circ}$ batter angle. The haul road was $12 \mathrm{~m}$ wide with a $10 \%$ grade applied to the shortest side. The haul road polygons were adjusted to provide bench access both inside and outside of the road. The complete pit design was intersected and cropped with current topography.

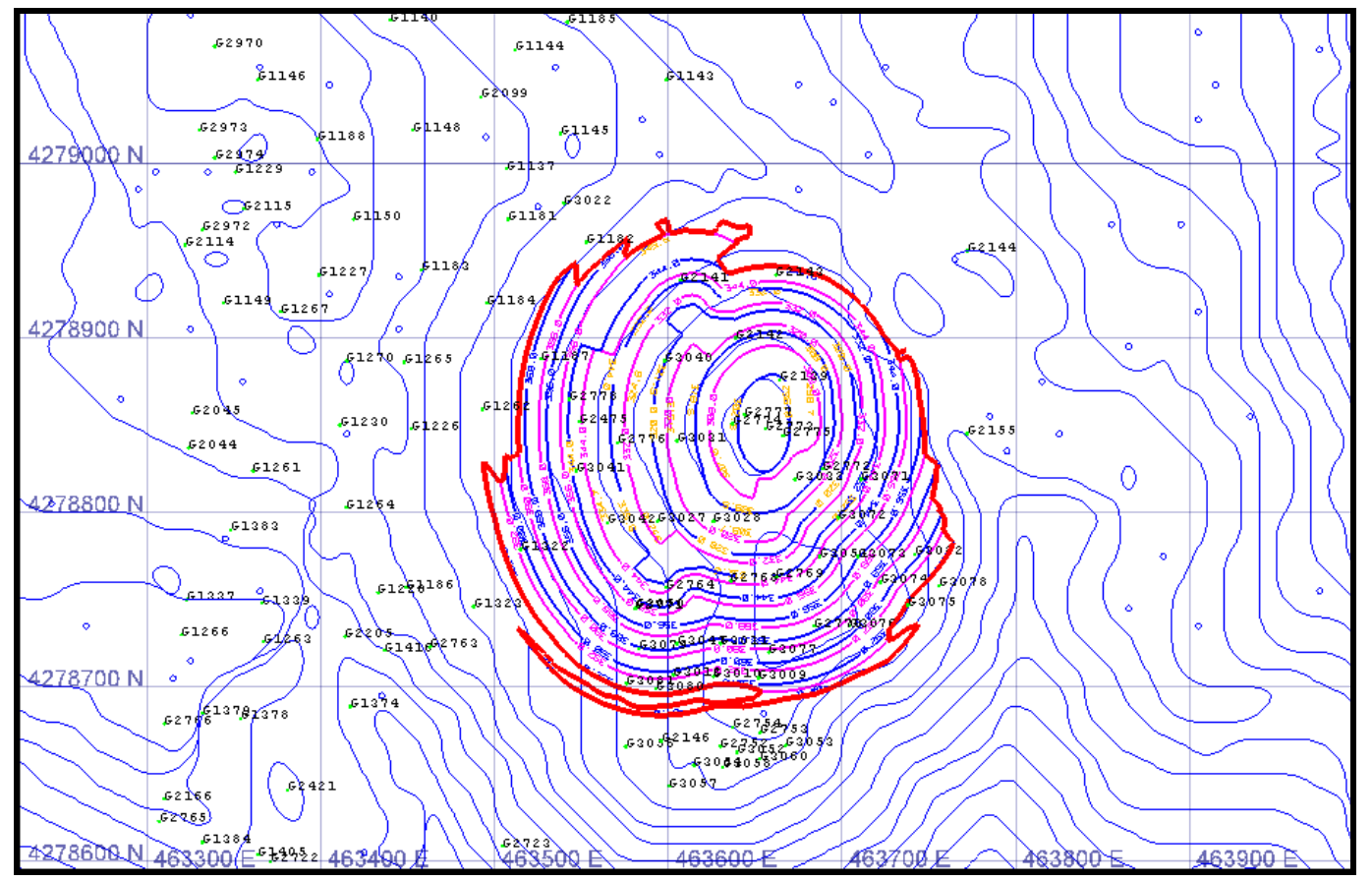

Figure 8 - Optimum pit contours and final pit design.

\section{Resources / Reserves Reporting}

In order to compare the estimated reserves with the production figures for the period up to the end of 2012, a solid triangulation model was generated representing the volume of the actual excavation at the end of this period. Table 3 gives a summary of the total estimated resources for the NA Akres deposit, the estimated reserves inside the solid model and the actual reserves mined from the same volume. There is some over-estimation of tonnage combined with an underestimation of grade which translates to very similar nickel content in both cases $(6,005 \mathrm{t}$ actual versus $6,344 \mathrm{t}$ estimated).

\section{Conclusions}

This paper discussed most aspects of the application of mine planning software to the evaluation of mineral resources and mineral reserves of the sedimentary nickel deposits in Euboea. The implementation of commercial mine planning software produced results that increased confidence as to the available resources, aided the configuration of the mining methods applied, and helped in planning future mining operations by developing different mining scenarios with speed and clarity. The adoption of a geostatistical approach to grade/reserves estimation increased confidence in the produced results and reduced the risks associated with the estimates. The use of a pit optimisation 
tool helped convert resources to reserves with more confidence and in a more standardised fashion that is widely accepted by the mining industry. The procedures described in this paper have been adopted with minor adjustments to other nickel deposits exploited by LARCO SA in other areas of Greece.

Table 3 - Summary of ore resources and reserves from NA Akres deposit.

\begin{tabular}{|c|c|c|c|c|c|c|}
\hline & \multicolumn{2}{|c|}{$\begin{array}{c}\text { Total Estimated } \\
\text { Resources }\end{array}$} & \multicolumn{2}{c|}{$\begin{array}{c}\text { Estimated Reserves } \\
(\mathbf{2 0 1 1 - 2 0 1 2 )}\end{array}$} & $\begin{array}{c}\text { Actual } \\
\text { Reserves } \\
(\mathbf{2 0 1 1 -} \\
\mathbf{2 0 1 2})\end{array}$ \\
\cline { 2 - 7 } & Measured & Indicated & Measured & Indicated & Total & Total \\
\hline Ore Tonnage & 587,812 & $1,108,906$ & 96,851 & 479,925 & $\mathbf{5 7 6 , 7 7 7}$ & $\mathbf{5 0 8 , 9 2 6}$ \\
\hline Ore Ni Grade \% & 1.07 & 1.08 & 1.15 & 1.09 & $\mathbf{1 . 1 0}$ & $\mathbf{1 . 1 8}$ \\
\hline
\end{tabular}

\section{References}

Dagbert M., David M., Crozel D. and Desbarats A. 1983. Computing variograms in folded, stratacontrolled deposits, Geostatistics for Natural Resource Characterisation, NATO A.S.I. Series C, Volume 122, Part 1: 71-90.

Dowd P.A. 1986. Geometrical and geological controls in geostatistical estimation and orebody modelling, $19^{\text {th }}$ International Symposium on the Application of Computers and Operations Research in the Minerals Industries (APCOM), Colorado, Chapter 8: 81-94.

Duke J. and Hanna P. 1999. Computer-based Resource Estimation in Accordance with the 1999 JORC Code, White paper, ECS International Pty Ltd.

Joint Ore Reserves Committee. The Australasian Code for Reporting of Exploration Results, Mineral Resources and Ore Reserves (JORC 2012).

Kapageridis I. 2006. Use of Tetrahedral Modelling for Variography and Grade Estimation of a Structurally Deformed Phosphate Deposit. $11^{\text {th }}$ International Congress for Mathematical Geology (IAMG'06 - Quantitative Geology from Multiple Sources), International Association for Mathematical Geology, Liege.

Kapageridis I. Implementation of Reporting Code Guidelines for Mineral Resources and Mineral Reserves Using a General Mine Planning Package, in: 3rd International Conference on Sustainable Development Indicators in the Minerals Industry (SDIMI) - Entering the 'International Year of Planet Earth', Milos Conference Series, Milos 2007.

National Instrument 43-101, Standards of Disclosure for Mineral Projects, Canadian Securities Administrators, 2011.

Newton M.J. 1995. Structural analysis for folded deposits. Mining Magazine, August 1995.

Pan-European Reserves and Resources Reporting Committee, Pan-European Standard for Reporting of Exploration Results, Mineral Resources and Reserves (PERC Standard 2013).

Royle A.G. 1979. Plane projections of tabular orebodies for evaluation purposes, Transactions IMM, Volume 88: A87-A91.

Snowden D.V. 1996. Practical Interpretation of Resource Classification Guidelines, AusIMM Annual Conference "Diversity, the Key to Prosperity”, Perth.

SAMREC/SAMVAL Committee. South African Code for Reporting of Exploration Results, Mineral Resources and Mineral Reserves (SAMREC 2009). 